\title{
Recent Experimental Results for the Dark-Matter Search at the Large Hadron Collider
}

\author{
Hwidong YOO* \\ Department of Physics and Astronomy, Seoul National University, Seoul 08826, Korea \\ DongHee $\mathrm{KIM}^{\dagger}$ \\ Department of Physics, Kyungpook National University, Daegu 41566, Korea
}

(Received 3 July 2016 : revised 17 July 2016 : accepted 17 July 2016)

\begin{abstract}
Recent results from the dark-matter search at the Large Hadron Collider (LHC) are discussed in this review. Dark matter is one of the most veiled mysteries in current particle physics, and it cannot be explained using the Standard Model (SM). In attempts to discover dark matter, various theoretical and experimental approaches have been used and efforts have expended during the last several decades. Dark matter can be produced at the LHC, and the event signature from dark matter can be distinguished from the SM backgrounds. This paper presents recent results from the ATLAS (a toroidal LHC apparatus) and the CMS (compact muon solenoid) at the LHC on the mono-X search and the dark-photon search.
\end{abstract}

PACS numbers: 12.60.-i, 14.70.Pw

Keywords: Particle physics, LHC (large hadron collider), Dark matter, Dark photon

\section{강입자 가속기에서 암흑물질 탐사에 대한 최신 실험 결과}

\author{
유휘동* \\ 서울대학교 물리천문학부, 서울 08826 , 대한민국 \\ 김동희 \\ 경북대학교 물리학과, 대구 41566 , 대한민국 \\ (2016년 7월 3 일 받음, 2016년 7월 17일 수정본 받음, 2016년 7월 17 일 게재 확정)
}

\begin{abstract}
본 논문에서는 현재 강입자 가속기에서 연구되는 다양한 암흑물질 탐사에 대해 논의한다. 암흑물질은 표준모형으로 설명할 수 없는 현대 물리학 분야에서 가장 큰 미스터리중의 하나이며 이 암흑물질을 관측하기 위해 지난 수십년동안 많은 이론적, 실험적 연구가 진행되고 있다. 높은 에너지의 강입자 가속기 충돌 실험에서 이러한 암흑물질이 생성될 수 있으며, 이 암흑물질이 남기는 흔적을 찾아 표준모형으로부터 생성되는 배경사건들과 구분하면 암흑물질을 발견할 수 있을것으로 여겨지고 있다. 이 논문에서는 현재 강입자가속기 (large hadron collider, LHC) 의 ATLAS (a toroidal LHC apparatus) 및 CMS (compact muon solenoid) 실험에서 연구되고 있는 mono-X 및 암흑광자 탐사에 대해서 소개한다.
\end{abstract}

PACS numbers: 12.60.-i, 14.70.Pw

Keywords: 입자물리, 강입자가속기, 암흑물질, 암흑광자 


\section{I. 서 론}

암흑물질은 현재 여러 실험적 증거를 통해서 우주 전체 질량의 약 $25 \%$ 를 차지하고 있는 물질로 여겨지고 있으나 아직 그 존재를 직접적으로 관측하지 못하고 있다. 따라서 암흑물질의 직접적 관측은 최근 수십년간 입자물리 및 천 체입자물리학계를 관통하는 가장 큰 화두중의 하나였으며 다양한 각도로 이론 및 실험적 연구를 진행해 왔다. 여러 모형들 중에 가장 인기있는 것 중의 하나는 차갑고 (cold) 약 하게 반응하는 (weakly interacting) 암흑물질 모형 (weakly interacting massive particle, WIMP)이다. 이러한 약하게 반응하는 암흑물질들을 예측하는 이론들은 매우 다양한데 예를 들면 초대칭이론 (supersymmetry), 여분차원 (extra dimension), Little 힉스 모형 등이며 이 이론들에서 예측하 는 새로운 입자들은 이러한 성질을 갖는 암흑물질의 후보가 된다. 이렇게 약하게 반응하는 암흑물질의 경우 중성미자와 같이 검출기에서 거의 반응하지 않으므로 잃어버린 횡에너 지 (missing transverse energy, MET) 의 형태를 검출기에 남긴다. 이러한 MET 형태가 표준모형에서는 중성미자가 생성되는 사건에서 발생하므로 따라서 표준모형에서 예측 하는 모습을 자세히 연구하고 이를 벗어나는 사건 (event) 들을 찾아낼 경우 이는 암흑물질 발견의 강력한 증거가 될 수 있다. 또한 $\mathrm{MET}$ 를 연구하여 직접적으로 암흑물질을 탐사하는 것 뿐만 아니라 암흑물질과 힘의 상호작용을 매개 하는 입자를 추적하여 그 존재 및 성질을 연구하는 방법이 최근 10 여년간 많은 주목을 받고 있다. 소위 말하는 암흑광 자 탐사로 이 입자는 암흑물질의 전자기적 힘을 매개하는 입자로 여겨지고 있다.

암흑물질을 발견하기 위한 실험적 노력은 여러가지 형 태로 진행되고 있는데 서로 상호보완적이며 시너지 효과를 일으킬 것으로 예상되어 다음과 같이 다각도로 진행되고 있다. 첫번째는 직접적 검출 (direct detection) 이다. 이러 한 방식은 암흑물질이 아주 적지만 검출가능한 시그널을 생성하는 사건을 검출기로 검출하는 방식으로 WIMP가 핵과 산란되어 검출되거나 액시온 (axion)이 자기장에서 광자들과의 상호작용을 이용하여 관측하는 실험들이 이에 해당한다. 두번째는 간접적 검출 (indirect detection) 이다. 이러한 방식은 통상 암흑광자쌍이 소멸 (annihilation) 되면 서 생산하는 높은 에너지를 가진 입자들 (반입자, 중성미자, 광자등) 을 관측하는 실험이다. 이러한 직간접적 검출과는 다르게 입자가속기를 이용하여 암흑물질을 검출하는 방법도 있다. 입자가속기에서 입자들이 충돌할때 암흑물질들이 생

*E-mail: hdyoo@snu.ac.kr

${ }^{\dagger}$ E-mail: dkim@knu.ac.kr
성될 수 있으며, 위에 설명한 바와 같이 중성미자와 유사하 게 암흑물질은 검출기와 반응하지 않고 빠져나가므로 MET 를 자세히 관측하고 예측치와 비교하여 암흑물질을 발견할 수 있다. 입자가속기를 이용하는 방식이 직간접 검출과 비교하여 가지는 중요한 이점은 상대적으로 낮은 질량의 암흑물질을 찾는데 가장 효율적이라는 것이다. 그 이유는 낮은 질량의 암흑물질의 경우 가속기에서 높은 운동량을 가지고 생성될 것이기 때문에 큰 MET를 검출기에 남길 것이고 MET가 매우 큰 사건의 경우 전형적으로 배경사건 (background)이 적어서 암흑물질의 존재를 찾기가 상대적 으로 수월하다. 또한 단순히 암흑물질의 존재만을 발견하 는 것 뿐만아니라 이 입자의 상호작용을 매개하는 입자의 성질도 함께 이해할 수 있다는 점은 입자가속기 연구만이 가지는 중요한 장점이라고 할 수 있다. 본 논문에서는 현재 활발하게 연구가 진행되고 있는 대형 강입자 가속기 (large hadron collider, LHC) 의 결과를 다룬다.

스위스 제네바 외곽에 위치한 CERN 연구소에 건설된 대형 강입자 가속기 (LHC) 는 양성자를 높은 에너지로 가속 시켜 충돌시키고 그 충돌을 통해 생성되는 입자들의 사건을 이용하여 다양한 물리현상을 연구한다. 이 강입자 가속기는 2010 년부터 가동을 시작하여 2012년까지 (Run I: 20102012) 3 년간 $7 \mathrm{TeV}$ 및 $8 \mathrm{TeV}$ 의 질량중심 에너지로 충돌 실험을 진행하였다. $\mathrm{LHC}$ 에는 총 4 개의 검출기가 설치되어 있고 각 검출기별로 수천명의 물리학자로 구성된 대형 국제 공동연구단이 구성되어 있다. 이 중에 가장 일반적인 목적 (general-purpose) 을 가진 두 검출기, ATLAS (A Toroidal LHC ApparatuS) 와 CMS (Compact Muon Solenoid) 는 힉스보존 탐사 및 표준모형을 뛰어넘는 새로운 물리 현상 (Beyond Standard Model, BSM) 을 찾는 것을 주 목적으 로 건설되었으며 Run I 기간동안 $\mathrm{LHC}$ 로부터 약 $5 \mathrm{fb}^{-1}$ $(7 \mathrm{TeV})$ 와 $21 \mathrm{fb}^{-1}(8 \mathrm{TeV})$ 의 데이터를 획득 하였다. 이 데이터를 분석하여 연구한 결과를 바탕으로 마침내 2012년 힉스 보존을 발견하는 쾌거를 이루었다 $[1,2]$. 이는 표준모 형에서 예측해온 마지막 미발견 입자로 온 세계의 주목을 받은 대단한 과학적 업적이었다. 한국의 입자물리학자들도 $\mathrm{CMS}$ 검출기 건설당시부터 Korea-CMS 라는 공동 연구단을 구성하여 $\mathrm{CMS}$ 연구에 참여하고 있으며 힉스입자 발견을 비롯하여 많은 중요한 연구 결과에 기여하고 있다.

힉스입자 발견과 같은 대단한 과학적 성공에도 불구하고 표준모형으로는 설명할 수 없는 여러 난제들이 존재하고 있고, 암흑물질의 존재는 그 중 하나라고 할 수 있다. 암흑 물질에 대한 해답을 내놓기 위해 $\mathrm{LHC}$ 에서는 현재 다양한 연구를 수행하고 있다. $\mathrm{LHC}$ 를 이용한 암흑물질 탐사의 장점중의 하나는 높은 에너지의 충돌 데이터를 이용할 수 있고 특히 많은 데이터를 이용하므로 직간접적 검출에서 
주로 사용하는 천체입자물리학의 데이터와는 달리 이 데 이터가 갖는 불확실성 (uncertainty) 이 상대적으로 작고 특히 암흑물질의 질량에 대한 하한값 (lower bound limit) 이 존재하지 않아 넓은 질량 영역에 대해 다양한 형태로 접근할 수 있다. 기존에 주로 사용하던 방식은 유효 장론 (effective field theory, EFT) 을 기반으로 하는 접촉 상호 작용 (contact interaction) 의 모형을 이용하는 방식이었다. 이러한 EFT는 시그널의 MET 분포가 암흑물질의 입자의 질량에 강하게 영향을 받으며 따라서 이러한 현상의 생성 비 율 (production rate) 만이 자유 매개입자 (free parameter) 로 남는다. EFT 방식의 결과는 다른 비충돌실험의 결과들 과 직접적으로 생성비율을 비교할 수 있는 장점을 가지고 있다. 반면에 $\mathrm{EFT}$ 는 표준모형 입자와 암흑물질 입자를 매 개하는 입자가 무거울 것을 가정하고 있다. 이 매개입자가 무겁지 않은 경우에는 EFT를 이용하여 설명하기 어려우며 매개입자의 현상들을 좀 더 자세히 묘사할 수 있는 모형을 필요로 한다. 이러한 모형은 암흑물질이 생성되는 "간소화 모형 (simplied model)"으로 불리며 BSM 입자들과 상호 작용을 설명한다. 이론적으로 많은 간소화 모형이 존재하며 최근의 추세는 $\mathrm{EFT}$ 방식의 접근에 대한 확장으로 간소화 모형을 이용한 탐사가 $\mathrm{LHC}$ 에서 진행되고 있으며 암흑물질 탐사의 분석상 디자인이나 최적화등에 중요하게 사용되고 있다.

본 논문에서는 최근 입자물리학계에서 가장 많은 주목을 받고 있는 “모형에 독립적인 탐사" (소위 mono-X 탐사라 불리는) 와 "암흑광자 탐사" 에 대한 최신 연구 결과들을 $\mathrm{LHC}$ 의 ATLAS 및 $\mathrm{CMS}$ 실험을 중심으로 소개 한다.

\section{II. 모형에 독립적인 암흑물질 탐사 (mono-X search)}

암흑물질이 $\mathrm{LHC}$ 에서 생산될 수 있는 일반적인 형태는 두 개의 암흑물질이 생성되는 소위 쌍생성 (pair-production) 이다. 이때 초기 (initial state) 혹은 말기 상태 (final state) 에서 복사 (radiation) 가 일어나게 되는데, 이러한 복사를 통해 발생하는 입자는 글루온 (gluon), 광자 (photon), 약력 매개입자 (Weak gauge boson: $\mathrm{W}, \mathrm{Z}$ 보존) 등이다. 쌍생성 된 암흑물질은 검출기에서 반응을 일으키지 않으며 $\mathrm{MET}$ 의 형태를 검출기에 남기게 된다. 따라서 $\mathrm{MET}$ 와 함께 글루온, 광자 혹은 $\mathrm{W}$ 나 Z 보존이 같이 존재하는 사건을 찾고 이러한 사건들에서 표준모형으로부터 생성된 사건들을 구분해 내면 암흑물질로부터 생성된 사건을 찾을 수 있을 것으로 여겨진 다. 이러한 연구를 소위 mono-X $(\mathrm{X}=$ gluon, photon, $\mathrm{W}$ or Z etc.) 탐사라 하며 상대적으로 큰 산란단면적 (crosssection) 및 적은 표준모형 배경사건를 가지고 있어 만약 암 흑물질이 이러한 형태로 존재한다면 매우 높은 발견 확률을 가진 연구 주제라고 할 수 있다. 더우기 연구에서 MET를 이용하기 때문에 발생시키는 암흑물질의 성질은 중요하지 않으므로 암흑물질의 이론 모형에 독립적인 연구를 진행할 수 있는 장점이 있다. 이러한 높은 발견 확률 및 장점들로 인해 현재 ATLAS 및 CMS에서 암흑물질 탐사 연구에서 가장 핵심적인 연구 주제라고 할 수 있다.

이 연구 중 대표적인 예로서 mono-jet 탐사가 있다. 여 기서 jet는 검출기를 통해 관측할 수 있는 물리량의 하나로 글루온이 강입자 다발로 붕괴하는 현상 (hadronization) 을 통해 여러 입자들의 흔적을 검출기에 남기고 이를 바탕으로 재구성한 물리량이다. 이러한 mono-jet 탐사는 암흑물질로 부터 오는 커다란 $\mathrm{MET}$ 와 상대적 높은 에너지를 가진 jet 가 존재하는 사건을 고르고 표준모형의 배경사건으로부터 오는 예상치를 계산하여 실제 데이터에서 표준모형의 배경 사건을 초과하는 사건들이 존재하는지의 여부를 확인한다. 이 연구에서 주요 표준모형 배경사건은 $\mathrm{Z}$ 보존이 하나의 jet 과 함께 생성되는 사건이다. 이때 Z 보존이 두개의 중 성미자로 붕괴할 경우 이 사건은 암흑물질생성으로부터 일어나는 mono-jet현상과 검출기 상에서 동일한 흔적을 남기므로 표준모형으로부터 발생하는 이 현상을 얼마나 잘 이해하느냐가 이 연구의 주요 변수중 하나이다. Fig. 1은 최근 $\mathrm{ATLAS}$ 와 $\mathrm{CMS}$ 실험의 $13 \mathrm{TeV}$ 및 $8 \mathrm{TeV}$ 결과를 보 여준다 [3,4]. 각 실험 결과는 여러 암흑물질 모형의 매개변 수들에 의존하는 결과로 해석해서 보여주며 또한 여러 다른 존재하는 실험들의 결과들과 비교하였다. 그림에서와 같이 $\mathrm{ATLAS}$ 와 $\mathrm{CMS}$ 결과 모두 암흑물질과 표준모형입자간의 상호작용에 대하여 ( $\chi$-nucleon cross section) 중요한 구속 조건을 부여하며 직접 암흑물질을 탐사하는 다른 실험들이 도달하기 어려운 매개변수 영역까지 제한치를 제공한다.

mono-photon 탐사는 위의 mono-jet 탐사와 유사한 물 리적 현상으로 발생하나 여기서 복사되는 입자가 글루온 이 아닌 광자이다. 이는 앞서 설명한 바와 같은 현상을 통해 생성되는 사건인데 말기 상태에서 커다란 $\mathrm{MET}$ 와 하나의 광자를 가진 사건을 찾는다. 이 현상이 일어날 수 있는 빈도수는 전자기 결합상수에 의해 그 산란단면적의 크기가 결정되며 이 결합상수는 강력의 결합상수에 비해 작기 때문에 산란단면적은 mono-jet 탐사에 비하면 상대 적으로 작다. 따라서 이러한 현상으로 부터 오는 사건의 수는 같은 데이터 안에서 mono-jet 탐사에 비하면 적을 수 밖에 없으나 ATLAS 나 CMS 에서 광자를 검출하는 검출 기는 jet을 검출하는 검출기에 비해 높은 해상도 (detector resolution) 을 제공하므로 상대적으로 작은 산란단면적임 

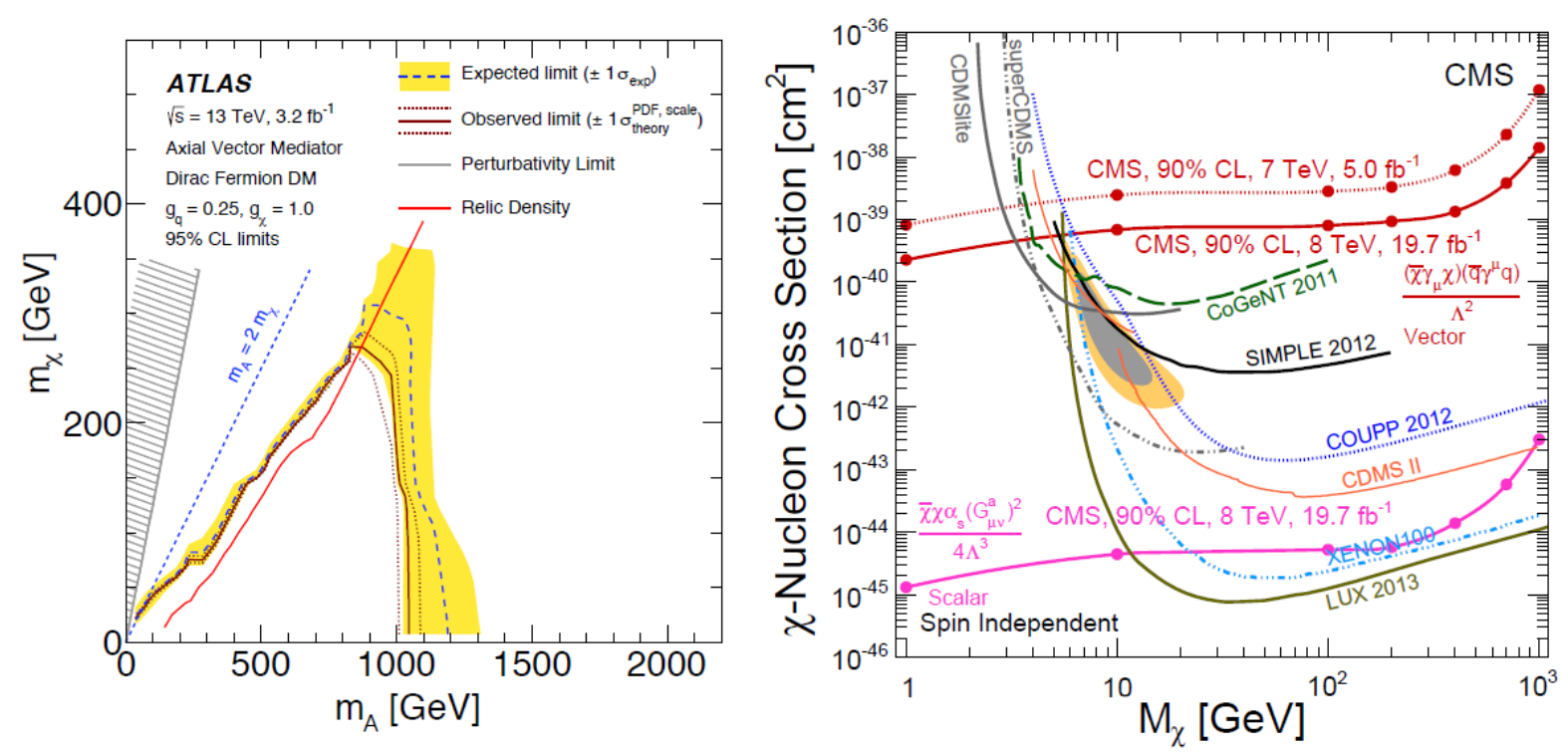

Fig. 1. (Color online) Left plot shows ATLAS results for the mono-jet search. The plot is the observed and expected 95\% CL exclusion contours in the $\mathrm{m}_{\chi}-\mathrm{m}_{A}$ parameter plane for a simplified model at $13 \mathrm{TeV}$ [3]. Right plot shows CMS results for the same search at $8 \mathrm{TeV}$. The upper limits on the DM-nucleon cross section at 90\% CL as a function of DM particle mass is shown in the plot. The plot also contains the public results from other experiments. This limit is calculated for the vector and scalar operators from the previous CMS analysis [4].
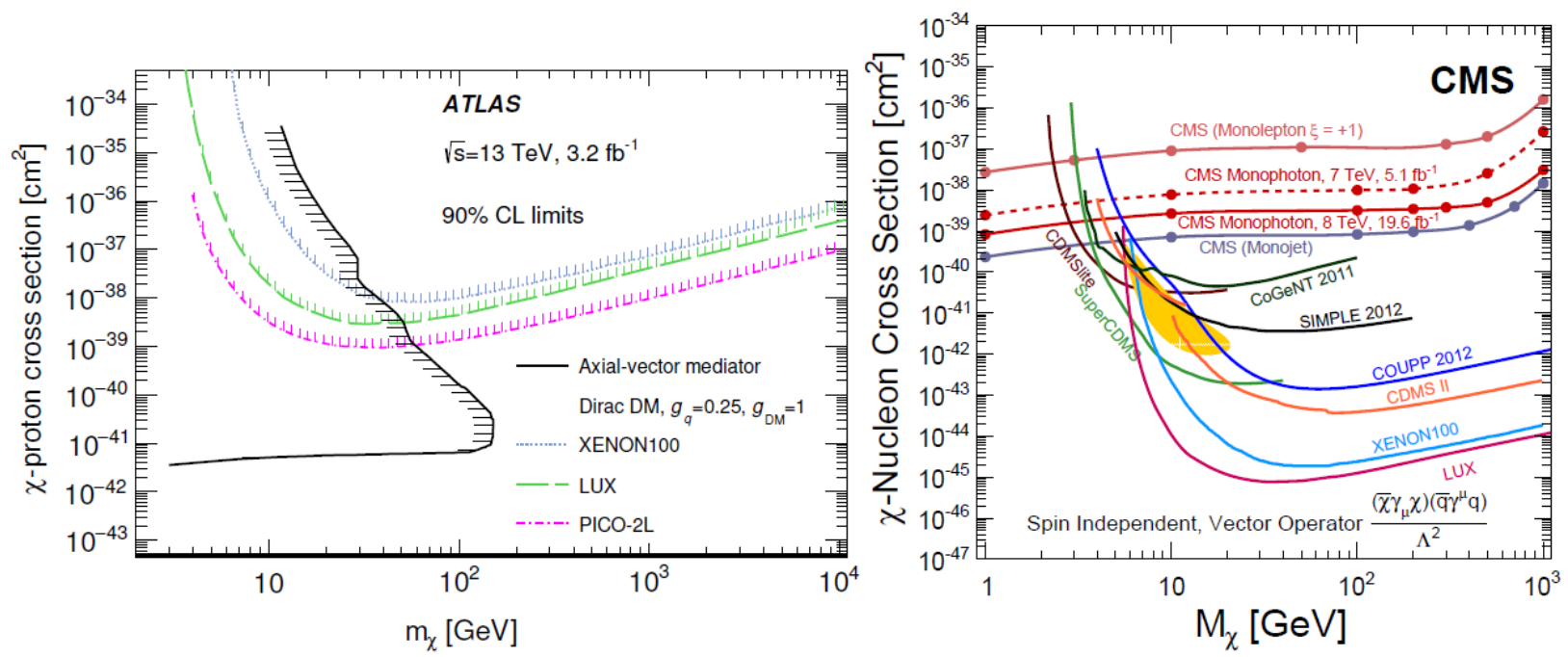

Fig. 2. (Color online) Left plot: ATLS results at $13 \mathrm{TeV}$ for the mono-photon search. This plot shows the 90\% CL exclusion limit on the $\chi$-proton scattering cross section as a function of the dark matter mass in the simplified model. The model of dark matter with axial-vector operator, Dirac DM and couplings $g_{q}=0.25$ and $g_{\chi}=1$ is used to calculate the exclusion limit and the results are compared to three direct dark matter search experiments [5]. Right plot shows CMS results for the mono-photon search and the format of this plot is similar to the right plot of Fig 1. This result shows the upper limits on the $\chi$-nucleon cross section at $90 \% \mathrm{CL}$ as a function of DM particle mass at $8 \mathrm{TeV}$. The plot also contains the public results from other experiments [6].

에도 불구하고 이러한 장점을 가지고 있다. 이 탐사에서 전형적인 표준모형의 배경사건은 $\mathrm{Z}$ 보존과 광자의 쌍생성 ( $\mathrm{Z} \gamma$ diboson production) 으로 부터 오는데, 이때 $\mathrm{Z}$ 보존 은 앞서 mono-jet 채널과 마찬가지로 두개의 중성미자로 붕괴하여 검출기 상에서 같은 형태의 사건을 남기게 된다. 이러한 $\mathrm{Z} \gamma$ 이외에도 다양한 배경사건들 $(\mathrm{W} \gamma, \gamma+\mathrm{jets}$ 등)
으로부터 오는 배경사건들을 자세히 이해하여 암흑물질로 부터 생성되는 사건들을 구분해야 한다. Fig. 2 는 monophoton 탐사에 대해 최근 ATLAS와 CMS 실험의 $13 \mathrm{TeV}$ 및 $8 \mathrm{TeV}$ 결과를 보여준다 $[5,6]$. 앞서 mono-jet 탐사에서 논의한 Fig. 1과 유사하게 각 실험 결과는 여러 암흑물질 모형과 표준모형입자간의 상호작용에 대한 산란단면적의 

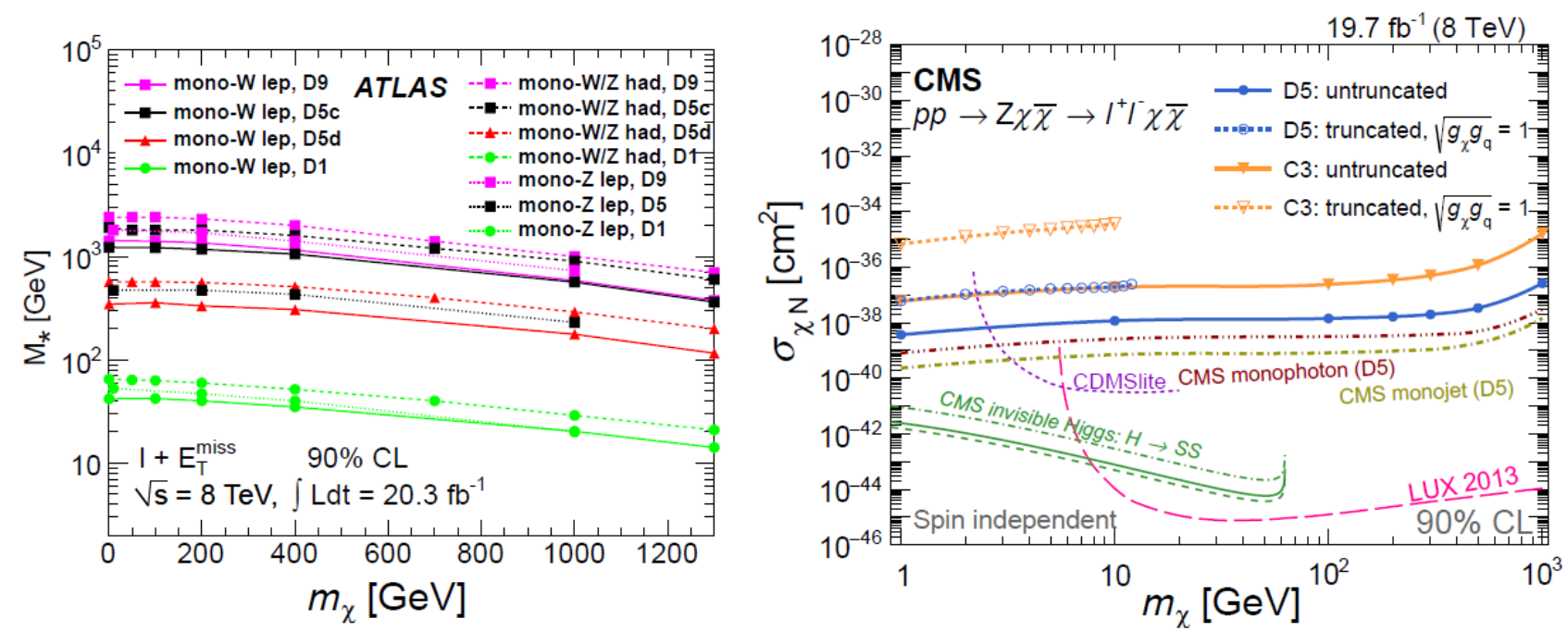

Fig. 3. (Color online) Left plot: ATLAS results at $8 \mathrm{TeV}$ for the mono-W search. This plot shows observed limits at $90 \% \mathrm{CL}$ on $\mathrm{M}_{*}$ as a function of $\mathrm{M}_{\chi}$, where the $\mathrm{M}_{*}$ is the mass scale of a new SM-DM interaction expressed in an effective field theory. The results are based on the combination of the electron and muon channels and compared to the previous ATLAS searches for hadronic and leptonic decays [7]. Right plot: CMS results at 8 TeV for the mono-Z search. This plot shows the $90 \%$ CL upper limits on the DM-nucleon cross section as a function of $\mathrm{M}_{\chi}$. The plot also contains the public results from other experiments [8].

변수로 제한치를 계산하였다. 이러한 결과는 암흑물질의 질량과 같은 매개변수들에 의존하는 결과로 해석하여 여러 다른 존재하는 실험들의 결과들과 비교하였다. 그림에서와 보여지는 것과 같이 mono-photon 탐사 결과 역시 mono-jet 과 마찬가지로 다른 실험들에서 도달하지 못하는 암흑물질 질량 영역에 대해 제한치를 제공하는 것을 알수 있다.

부가적으로 위의 mono-jet이나 mono-photon 탐사에서 복사로 생성되는 글루온이나 광자이외에 약력을 매개하는 게이지 보존인 $\mathrm{W}$ 보존이나 $\mathrm{Z}$ 보존이 이러한 복사를 통해 생성될 수 있다. 이 채널은 위에서 다룬 두 채널에 비해 상대적으로 매우 작은 산란단면적을 가지게 되나 중요한 장점 중의 하나는 여기서 생성된 $\mathrm{W}$ 보존이나 $\mathrm{Z}$ 보존이 전 자나 뮤온 같은 경입자로 붕괴할 수 있고 경입자는 ATLAS 나 $\mathrm{CMS}$ 검출기에서 가장 좋은 해상도를 갖는 입자라는 점이다. 이렇게 높은 해상도로 검출할 수 있는 경입자는 검출기로 부터 오는 계통오차 (systematic uncertainty) 를 현저히 줄 일 수 있고 글루온이나 광자를 이용한 연구보다 훨씬 더 정확한 측정이 가능하다. 또한 표준모형으로부터 발 생하는 배경사건도 상대적으로 더 적어 배경사건들로 부터 암흑물질의 시그널을 찾는데 더 유리 할 수 있다. mono-W 의 경우 $\mathrm{W}$ 보존이 한개의 경입자와 중성미자로 붕괴하고 mono-Z의 경우 Z 보존이 두개의 서로 다른 전하의 경입자 로 붕괴하게 된다. 따라서 두 채널에서는 각각 한개 및 두 개의 경입자가 최종 상태에서 존재하게 되고 이러한 입자를 가지고 있는 사건을 찾아 표준모형의 주요 배경사건들로 분리하여 암흑물질의 존재를 찾는다. Fig. 3 은 mono-W 및
mono-Z 탐사에 대해 최근 ATLAS와 CMS 실험의 $8 \mathrm{TeV}$ 결과를 보여준다 $[7,8]$. 앞서 mono-jet과 mono-photon 탐 사에서 논의한 결과들과 비슷하게 여러 암흑물질 모형과 표준모형입자간의 상호작용에 대한 산란단면적의 변수로 제한치를 계산하였다. 이러한 결과는 암흑물질의 질량과 같은 매개변수들에 의존하는 결과로 해석하여 여러 다른 존재하는 실험들의 결과들과 비교하였다.

마지막으로 위의 mono-W나 mono-Z 탐사에서 $\mathrm{W}$ 나 Z 가 경입자가 아닌 강입자 다발로 붕괴하는 결과에 대해 간략하게 소개한다. 이 채널은 앞서 설명한 간소화 모형을 이용한 연구결과로 이 모형에서는 스핀0나 스핀1을 가진 매 개입자가 암흑물질로 붕괴하는 형태로 넓은 분포의 질량에 대하여 다룬다. 이때 강입자 다발은 jet의 형태로 검출기에 남게되고 특히 $\mathrm{W}$ 나 Z는 두개의 jet로 붕괴하게 되는데 높은 운동량을 가지고 생성되는 $\mathrm{W}$ 나Z에서 만들어지는 jet은 같 은 방향으로 부스트 된다. 이는 검출기에서 마치 한개의 jet 과 유사한 형태를 띄게 되는데 이를 구분하기 위한 기술적 방법을 "jet 내부구조 (jet substructure)" 방법이라고 한다 [9]. 이 방법을 통하여 내부가 두개의 jet으로부터 생성된 jet 인지 아니면 하나의 jet으로부터 생성된 jet 인지를 구분하여 암흑물질로부터 생성된 사건과 배경사건을 분리하게 된다. 전형적인 시그널은 하나의 jet 내부구조를 가진 jet과 큰 $\mathrm{MET}$ 를 남기며 위에서 설명한 mono-jet 탐사의 사건과는 jet 내부구조를 이용하여 구분한다. 관련 연구 결과는 현재 예비 결과가 발표되어 있으며 [10] 논문 준비중에 있다. 

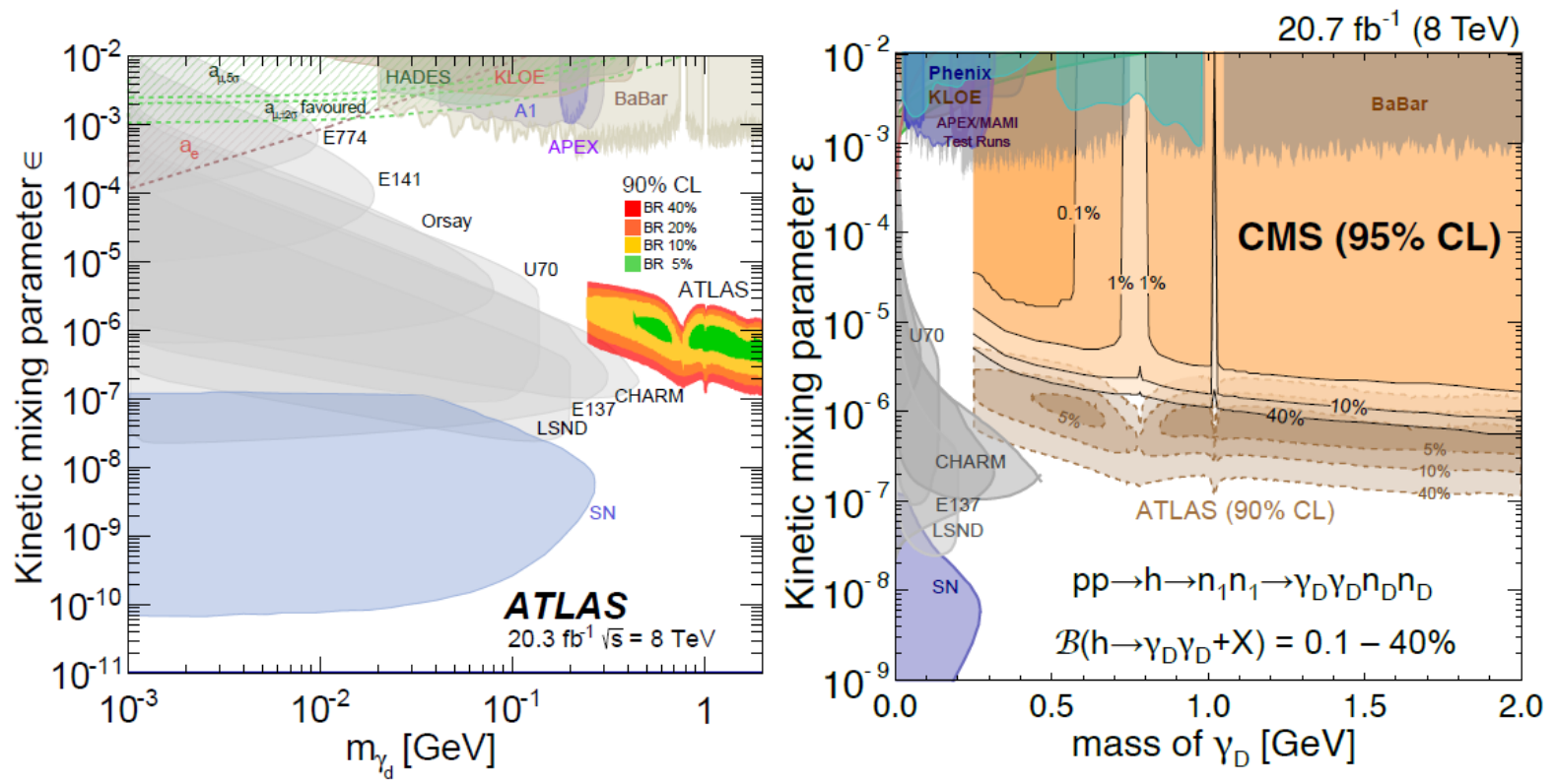

Fig. 4. (Color online) Left plot shows ATLAS $8 \mathrm{TeV}$ results for $90 \% \mathrm{CL}$ exclusion regions with parameter space for dark photons as a function of the $\gamma_{d}$ mass and of the kinetic mixing parameter $\epsilon$. The plot also contains exsiting 90\% CL exclusion regions from other experiments [17]. Right plot shows CMS 8 TeV results for 95\% CL upper limits on $\sigma\left(\mathrm{pp} \rightarrow \mathrm{h} \rightarrow 2 \gamma_{\mathrm{D}}+X\right) B\left(\mathrm{a}_{1} \rightarrow 2 \mu\right)$ in the parameter plane of $\varepsilon$ and $m_{2 \gamma_{D}}$ for the dark SUSY scenarios, where $m_{n 1}=10 \mathrm{GeV}$ and $m_{n_{D}}=1 \mathrm{GeV}$. In the plot, constraints from other experiments showing the $90 \%$ CL exclusion contours [18].

\section{III. 암흑광자 탐사(dark photon search)}

암흑광자는 2000 년대 후반 처음 이론적으로 존재 가능 성이 제안된 입자로, 암흑물질의 전자기적 힘을 매개하는 입자를 가리킨다 [11]. 이러한 암흑 전자기력을 매개하는 암흑광자는 그 질량이 매우 작을 것으로 여겨지고 있으며, 만약 암흑광자가 발견된다면 베일에 쌓여 있는 암흑물질의 성질을 이해하고 직접적으로 관측할 수 있는 중요한 열쇠가 될 것이다. 그 존재를 찾기위해 현재 전세계적으로 다양한 실험이 진행되고 있는데 이러한 암흑광자가 만일 실제로 존재한다면, $\mathrm{LHC}$ 에서도 이 입자를 관측 할 수 있다. 현재 가속기 실험에서 사용되고 있는 검출기는 기본적인 표준 모형 입자들 (경입자, 광자, 대전입자 등) 을 검출하는데 목적을 두고 만들어 졌으며 특히 암흑광자가 발견된 적이 없어 그 성질을 알지 못하므로 직접적인 검출은 현재로서는 불가능하다. 하지만 이 암흑광자가 표준모형에서의 입자들 과 약하게 상호작용 할 수 있으며 표준모형의 광자와 서로 섞임 (mixing) 현상을 일으킬 수 있는데 이러한 현상들을 통해 관측이 가능할 것으로 예측되고 있다.

이렇게 두 개의 양성자가 충돌할때 생성되는 암흑광자를 관측하기 위한 다양한 모형들이 연구되고 있다. 그 중 최근 몇년간 많은 입자 물리학자들의 관심을 받고 있는 방법은 2012 년 발견된 힉스 보존 $[1,2]$ 과 결합을 이루는 형태이다
[12-15]. 이러한 모형에 따르면 LHC에서 생성된 힉스 보 존은 두 개의 암흑광자로 붕괴되며 이 암흑광자는 질량이 매우 가볍고 표준모형의 입자들과 아주 약하게 상호작용 하게 된다. 따라서 매우 적은 확률로 표준모형 입자들과의 상호작용을 통해 붕괴하게 되면 이러한 암흑광자로부터 붕괴된 표준모형입자들을 검출기로 검출하여 암흑광자의 존재를 찾을 수 있다.

현재 가동되고 있는 $\mathrm{LHC}$ 에서 이 모형과 관련한 연구가 활발히 진행되고 있으며, 이미 Run I 데이터를 이용하여 분석한 실험 결과를 담고 있는 여러편의 논문들이 ATLAS 와 CMS에서 발표 되었다 [16-19]. 이 논문들에서는 힉스 보존이 두 개의 암흑광자로 붕괴하고 각 암흑광자가 두개의 뮤온이나 전자등의 경입자로 붕괴하는 현상을 연구하였다. 따라서 두 개의 양성자 충돌로 일어나는 사건 (event) 들 속에서 암흑광자가 생성된 현상과 관련된 사건들은 최종적 으로 총 네 개의 경입자가 존재해야 한다. 이러한 네 개의 경입자를 가지고 있는 사건을 분석하여 표준모형의 배경 사건과 실제 데이터가 얼마만큼 차이나는 지를 측정하여 배경사건을 초과하는 현상이 발견되면 이는 암흑광자의 존재의 강력한 증거가 된다.

이 연구들에서 실험적인 어려움은 다음과 같은 현상때 문이다. 힉스 보존의 질량은 암흑광자에 비해 상대적으로 훨씬 높은 $125 \mathrm{GeV}$ 이고 암흑광자의 질량은 수 $\mathrm{MeV}$ 에서 수 
$\mathrm{GeV}$ 에 이를 것으로 예측되고 있기 때문에 암흑광자로 부터 붕괴되서 생성되는 경입자들은 같은 방향으로 날아가는 현 상이 일어나게 된다 (부스트 현상). 현재 CMS나 ATLAS 검출기는 부스트되지 않는 평범한 현상으로부터 생성되는 뮤온이나 전자등을 측정하는데 최적화 되어 있다. 따라서 이러한 부스트 현상이 일어나면 뮤온과 전자를 정확하게 측정하고 획득할 수 있는 확률이 현저히 떨어지게 된다. 이를 해결하기 위해 각 논문별로 다양한 연구 기법을 적용 하였으며, 특히 경입자-제트 (lepton-jet) 라고 하는 새로운 형태의 재구성 방법을 이용하여 암흑광자의 붕괴로 부터 생성된 경입자를 찾는 확률을 높이려 노력하였다 [17].

현재까지 연구결과들에서는 표준모형에서 예상하는 예측 치에서 벗어나는 현상이 관측되지 않았으므로 암흑광자의 직접적 증거는 아직 발견되지 않았다. 각 연구 결과에서는 이를 바탕으로 암흑광자의 질량과 운동 (kinetic) 섞임 정 도에 대한 매개변수 $(\varepsilon)$ 를 이용하여 이 입자가 $95 \%(\mathrm{CMS})$ 혹은 $90 \%$ (ATLAS) 의 신뢰도로 존재하지 않을 확률에 대 한 값을 계산하였다. Fig. 4 는 각 논문에서의 결과를 보여 준다. 좌측의 그림은 $\mathrm{ATLAS}$ 의 $8 \mathrm{TeV}$ 데이터를 분석하여 획득한 결과이고 우측의 그림은 $\mathrm{CMS}$ 의 $8 \mathrm{TeV}$ 데이터를 분석하여 획득한 결과를 나타낸다. 그림에서 보이는 바와 같이 두 실험결과는 상호보완적이며 제외시킨 매개변수 영역도 서로 다르다. 이는 두 연구의 분석 방법 및 사용된 모형의 차이에서 기인한다. 암흑광자의 수명 (lifetime)은 $\varepsilon$ 과 암흑광자의 질량에 의존하며 두 연구에서 다른 수명의 모형으로 결과를 내었기 때문이다. 또한 두 그림에서 다른 실험으로부터 측정된 암흑광자가 $90 \%$ 로 존재하지 않을 확률에 대한 결과값도 함께 표시되었다. $\mathrm{LHC}$ 의 실험결과 들은 다른 실험들에서 제외 시키지 못한 매개변수 영역을 높은 확률적 신뢰도로 제외시켰다. 이로서 암흑광자가 존 재할 수 있는 매개변수 영역을 크게 줄여 향후 다음 단계의 암흑광자 탐사 실험의 중요한 길잡이 역할을 하였다.

\section{IV. 맺음말}

2013 년부터 2 년여간의 중단을 통해 한 단계 업그레이 드를 이룬 후 2015년부터 더 높은 질량중심 에너지로 재 가동을 시작한 $\mathrm{LHC}$ 는 mono-X에 관한 연구를 계속해서 진행하고 있으며 앞서 논의한 바와 같이 다양한 결과들이 이미 $13 \mathrm{TeV}$ 에서 생산되고 있다. 또한 암흑광자 탐사도 계속 활발히 연구되고 있으며 뮤온이나 전자로 붕괴하는 현상을 이용한 분석뿐 아니라 타우 경입자 ( $\tau$ lepton) 및 바닥쿼크 (b-quark) 들로 붕괴하는 현상을 이용하는 것으로 관련 연구를 확장하고 있다. 특히 2015년부터 강입자 가속
기는 Run I에서 사용된 질량중심 에너지 $(7,8 \mathrm{TeV})$ 보다 한층 높은 $(13 \mathrm{TeV})$ 에너지로 가동하고 있다. 이러한 높은 에너지는 암흑물질 및 암흑광자의 생성 확률을 높임으로서 더 많은 데이터를 획득할 수 있게 한다. 이를 통해 Run I 에서는 접근하기 어려웠던 여러 다른 붕괴 형태들로 연구를 확장하는 것이 가능해 지고 있다. 또한 2012년에 발견된 표준모형에서 예측한 힉스 보존이외에도 다른 종류의 힉스 보존이 존재할 것으로 예측하는 모형들이 있다. 이 모형이 맞는 다면 다양한 종류의 힉스 보존이 붕괴할때 암흑광자가 생성될 수 있으며, 이러한 연구도 현재 진행중에 있다.

이처럼 다양한 현상을 이용한 접근은 암흑물질의 존재에 대한 발견 가능성을 높이고 후속 연구에 방향성을 제시할 수 있다는 점에서 아주 중요하다고 할 수 있다. LHC는 약 4 년간 예정된 Run II (2015-2018) 기간동안 Run I 기간의 최소 4 배 이상의 데이터인 $100 \mathrm{fb}^{-1}$ 을 획득할 것으로 계획 되어 있으며 앞서 말한 바와 같이 휠씬 더 높은 질량중심 에너지로 받게 되므로 상대적으로 암흑물질의 생성 비율도 더 높게 된다. 이 데이터를 더욱 면밀히 분석하여 수년안에 암흑물질의 존재 증거를 $\mathrm{LHC}$ 에서 발견하길 기대해 본다.

\section{감사의 글}

본 연구는 서울대학교 신임교수 연구정착금으로 지원되 는 연구비에 의하여 수행되었습니다.

\section{REFERENCES}

[1] G. Aad, T. Abajyan, B. Abbott, J. Abdallah and S. A. Khalek et al. [ATLAS Collaboration], Phys. Lett. B 716, 1 (2012).

[2] S. Chatrchyan, V. Khachatryan, A. M. Sirunyan, A. Tumasyan and W. Adam et al. [CMS Collaboration], Phys. Lett. B 716, 30 (2012).

[3] ATLAS Collaboration, submitted to Phys. Rev. D, arXiv: 1604.07773

[4] V. Khachatryan, A. M. Sirunyan, A. Tumasyan, W. Adam and T. Bergauer et al. [CMS Collaboration], Eur. Phys. J. C 75, 235 (2015).

[5] M. Aaboud, G. Aad, B. Abbott, J. Abdallah and O. Abdinov et al. [ATLAS Collaboration], J. High Energy Phys. 06, 059 (2016).

[6] V. Khachatryan, A.M. Sirunyan, A. Tumasyan W. Adam and T. Bergauer et al. [CMS Collaboration], Phys. Lett. B 755, 102 (2016). 
[7] G. Aad, B. Abbott, J. Abdallah, S. Abdel Khalek and O. Abdinov et al. [ATLAS Collaboration], J. High Energy Phys. 09, 037 (2014).

[8] V. Khachatryan et al. [CMS Collaboration], Phys. Rev. D 93, 052011 (2016).

[9] S. D. Ellis, C. K. Vermilion and J. R. Walsh Phys. Rev. D 81, 094023 (2010).

[10] CMS Collaboration, submitted to J. High Energy Phys., arXiv:1607.05764

[11] N. Arkani-Hamed, D. P. Finkbeiner, T. R. Slatyer and N. Weiner, Phys. Rev. D 75, 015014 (2009).

[12] S. Gopalakrishna, S. Jung and J. D. Wells, Phys. Rev. D 78, 055002 (2008).

[13] H. Davoudiasl, H.-S. Lee, and W. J. Marciano, Phys. Rev. D 85, 115019 (2012).
[14] H. Davoudiasl, H.-S. Lee, I. Lewis and W. J. Marciano, Phys. Rev. D 88, 015022 (2013).

[15] D. Curtin, R. Essig, S. Gori and J. Shelton, J. High Energy Phys. 02, 157 (2015).

[16] S. Chatrchyan, V. Khachatryan, A. M. Sirunyan, A. Tumasyan and W. Adamet al. [CMS Collaboration], Phys. Lett. B 726, 564 (2013).

[17] G. Aad, B. Abbott, J. Abdallah, S. A. Khalek and O. Abdinov et al. [ATLAS Collaboration], J. High Energy Phys. 11, 088 (2014).

[18] V. Khachatryan, A. M. Sirunyan, A. Tumasyan, W. Adam and E. Asilar et al. [CMS Collaboration], Phys. Lett. B 752, 146 (2016).

[19] G. Aad et al. [ATLAS Collaboration], Phys. Rev. D 92, 092001 (2015). 